\title{
Modelling, Control design and Analysis of VSC based HVDC Transmission Systems
}

\author{
K. R. Padiyar \\ Department of Electrical Engineering \\ Indian Institute of Science \\ Bangalore, India 560012 \\ Email; krpyar@ee.iisc.ernet.in
}

\author{
Nagesh Prabhu \\ Department of Electrical Engineering \\ Indian Institute of Science \\ Bangalore, India 560012 \\ Email: knprabhu@ee.iisc.ernet.in
}

\begin{abstract}
The development of power semiconductors, specially IGBT's has led to the small power HVDC transmission based on Voltage Source Converters (VSCs). The VSC based HVDC transmission system mainly consists of two converter stations connected by a dc cahle.

This paper presents the modelling and control design of VSC based HVDC which uses twelve pulse three level converter topology. The reactive current injected by individual VSCs can be maintained constant or controlled to regulate converter bus voltage constant. While one VSC regulates the dc bus voltage the other controls the power flow in the dc link. Each VSC can have up to 4 controllers depending on the operating mode. The controller structure adopted for power controller is of PID type and all other controllers are of PI type. Each operating mode requires proper tuning of controller gains in order to achieve satisfactory system performance. This paper discusses a systematic approach for parameter optimization in selecting controller gains of VSC based HVDC.

The analysis of VSC based HVDC is carried using both D-Q model (neglecting harmonics in the output voltages of VSC) and three phase detailed model of VSC using switching functions. While the eigenvalue analysis and controller design is based on the D-Q model, the transient simulation considers both models. The analysis considers different operating modes of the converters.
\end{abstract}

Keywords: Voltage Source Converters(VSC), HVDC, Parameter optimization, Eigenvalue analysis, Transient simulation.

\section{INTRODUCTION}

The development of power semiconductors, specially IGBT's has led to the small power HVDC transmission based on Voltage Source Converters (VSCs). The VSC based HVDC installations has several advantages compared to conventional HVDC such as, independent control of active and reactive power, dynamic voltage support at the converter bus for enhancing stability, possibility to feed to weak AC systems or even passive loads, reversal of power without changing the polarity of dc voltage(advantageous in multiterminal dc systems) and no requirement of fast communication between the two converter stations [1]-[3].

Each converter station is composed of a VSC. The amplitude and phase angle of the converter $\mathrm{AC}$ output voltage can be controlhed simultaneously to achieve rapid, independent control of active and reactive power in all four quadrants. The control of both active and reactive power is bi-directional and continuous across the operating range. For active power balance, one of the converter operates on de voltage control and other converter on active power control. When dc line power is zero, the two converters can function as independent STATCOMs.

This paper presents the modelling and control design of VSC based HVDC which uses twelve pulse three level converter topology. The modelling of the system neglecting VSC is detailed (including network transients) and can be expressed in $\mathrm{D}-\mathrm{Q}$ variables or (three) phase variables. The modelling of VSC is based on (a) D-Q variables (neglecting harmonics in the output voltages of the converters) and (b) phase variables and the modelling of switching action in the VSC which also generates harmonics. The eigenvalue analysis and the controller design is based on the D-Q model while the transient simulation considers both models of VSC. Each VSC has a minimum of three controllers for regulating active and reactive power outputs of individual VSC. An additional controller at a VSC is required if the ac bus voltage is also to be regulated. Thus there are a large number of controller parameters to be tuned. A systematic approach [4], for parameter optimization in selecting the controller gains is discussed in detail.

The paper is organized as follows. The modelling of VSC based HVDC link is described in section II. The optimization of the controller parameters is covered in section III while a case study is presented in section IV. Section V presents the conclusions.

\section{MODELLING OF VSC BASED HVDC}

The VSC based HVDC transmission system mainly consists of two converter stations connected by a dc cable (see Fig. 1).

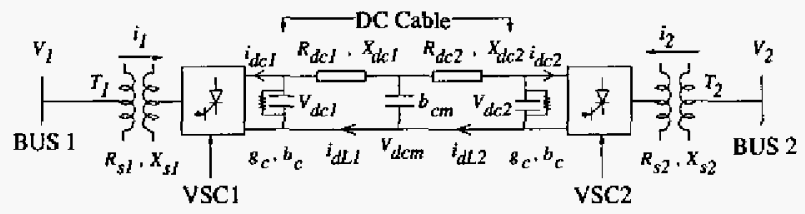

Fig. 1. Schematic representation of VSC based HVDC

Usually, the magnitude of ac output voltage of the converter is controlled by Pulse Width Modulation (PWM) without 
changing the magnitude of the dc voltage. However, the three level converter topology considered here can also achieve the goal by varying the dead angle $\beta$ with fundamental switching frequency [5], [6]. A combination of multi-pulse and three level configuration [7] is considered for both VSCs to have 12pulse converter with 3-level poles. The amplitude and phase angle of the converter $\mathrm{AC}$ output voltage can be controlled simultaneously to achieve rapid, independent control of active and reactive power in all four quadrants.

The detailed three phase model of converters is developed by modelling the converter operation by switching functions. (see Appendix-A).

\section{A. Mathematical model in $D-Q$ frame of reference}

When switching functions are approximated by their fundamental frequency components neglecting hamonics, VSC based HVDC can be modelled by transforming the three phase voltages and currents in to D-Q variables using Kron's transformation [8], [9]. The equivalent circuit of a VSC viewed from the AC side is shown in Fig. 2.

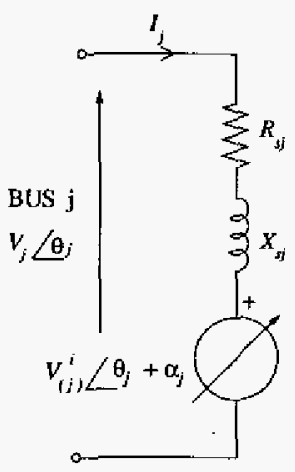

Fig. 2. Equivalent circuit of a VSC viewed from the AC side

In Fig. 2, $R_{s j}, X_{s j}$ are the resistance and reactance of the interfacing transformer of $\mathrm{VSC}_{j}$. The magnitude control of $j^{\text {th }}$ converter output voltage $V_{(j)}^{i}$ is achieved by modulating the conduction period affected by dead angle $\beta_{j}$ of individual converters. One of the converter controls dc voltage while the other converter controls dc link power.

The output voltage of $j^{\text {th }}$ converter can be represented in $D-Q$ frame of reference as:

$$
\begin{gathered}
V_{(j)}^{i}=\sqrt{V_{D(j)}^{2}+V_{Q(j)}^{2}} \\
V_{D(j)}=k_{m j} V_{d c j} \sin \left(\theta_{j}+\alpha_{j}\right) \\
V_{Q(j)}=k_{m j} V_{d c j} \cos \left(\theta_{j}+\alpha_{j}\right)
\end{gathered}
$$

Where, $k_{m j}=k^{\prime} \cos \left(\beta_{j}\right), k^{\prime}=k \rho_{j} \frac{V_{d c k}}{V_{a c b}, k=\frac{2 \sqrt{6}}{\pi}}$ for a 12 pulse converter, $\rho_{j}$ is the transformation ratio of the interfacing transformer $T_{j}$ and $V_{d c b}$ and $V_{a c b}$ are the base voltages of dc and ac sides respectively. $\alpha_{j}$ is the angle by which the fundamental component of $j^{t h}$ converter output voltage leads the $j^{\text {th }}$ ac bus voltage $V_{j}$. With the two converter VSC based HVDC system, $j=1,2$.

The dc side capacitors are described by the dynamical equations as,

$$
\begin{gathered}
\frac{d V_{d c 1}}{d t}=-\frac{g_{c} \omega_{b}}{b c} V_{d c 1}-I_{d c 1} \frac{\omega_{b}}{b c}-I_{d L 1} \frac{\omega_{b}}{b c} \\
\frac{d V_{d c 2}}{d t}=-\frac{g_{c} \omega_{b}}{b c} V_{d c 2}-I_{d c 2} \frac{\omega_{b}}{b c}+I_{d L 2} \frac{\omega_{b}}{b c} \\
\frac{d V_{d c m}}{d t}=I_{d L 1} \frac{\omega_{b}}{b c m}-I_{d L 2} \frac{\omega_{b}}{b c m}
\end{gathered}
$$

where,

$I_{d c 1}=-\left[k_{m 1} \sin \left(\theta_{1}+\alpha_{1}\right) I_{D(1)}+k_{m 1} \cos \left(\theta_{1}+\alpha_{1}\right) I_{Q(1)}\right]$ $I_{d c 2}=-\left[k_{m 2} \sin \left(\theta_{2}+\alpha_{2}\right) I_{D(2)}+k_{m 2} \cos \left(\theta_{2}+\alpha_{2}\right) I_{Q(2)}\right]$ $I_{D(1)}$ and $I_{Q(1)}$ are $\mathrm{D}-\mathrm{Q}$ components of converter-1 current $I_{1}$.

$I_{D(2)}$ and $I_{Q(2)}$ are $\mathrm{D}-\mathrm{Q}$ components of converter-2 current $I_{2}$.

$I_{d L 1}$ and $I_{d L 2}$ are the DC cable currents in the left and right hand side sections of the cable.

\section{B. Converter control}

The Fig. 3 shows the schematic representation for converter control. In reference [10], [11], the dynamical equations of the current control are dealt with in detail. The reactive current reference $\left(I_{R(j) \text { ref }}\right)$ of $j^{\text {th }}$ converter can be kept constant or regulated to maintain the respective bus voltage magnitude at the specified value. The active current reference $\left(I_{p(j)}\right.$ ref $)$ can be either obtained from DC voltage controller or power controller.

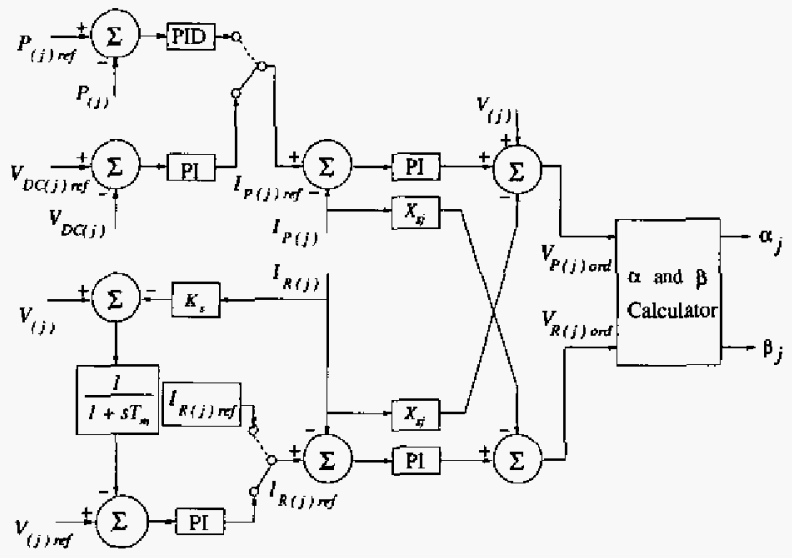

Fig- 3. Converter controller

Referring Fig. 3, active and reactive currents for $j^{\text {th }} \mathrm{con}$ verter are defined as

$$
\begin{gathered}
I_{P(j)}=I_{D(j)} \sin \left(\theta_{j}\right)+I_{Q(j)} \cos \left(\theta_{j}\right) \\
I_{R(j)}=-I_{D(j)} \cos \left(\theta_{j}\right)+I_{Q(j)} \sin \left(\theta_{j}\right)
\end{gathered}
$$


and $\alpha_{j}$ and $\beta_{j}$ are calculated as

$$
\begin{gathered}
\alpha_{j}=\tan ^{-1}\left[\frac{V_{R(j)(o r d)}}{\left.V_{P(j)(o r d)}\right)}\right] \\
\beta_{j}=\cos ^{-1}\left[\frac{\sqrt{V_{P(j)(o r d)}^{2}+V_{R(j)(o r d)}^{2}}}{k^{\prime} V_{d c(j)}}\right] \\
V_{P(j)}=V_{D(j)} \sin \left(\theta_{j}\right)+V_{Q(j)} \cos \left(\theta_{j}\right) \\
V_{R(j)}=V_{D(j)} \cos \left(\theta_{j}\right)-V_{Q(j)} \sin \left(\theta_{j}\right)
\end{gathered}
$$

$V_{P(j)}$ and $V_{R(j)}$ are the in phase and quadrature components of $V_{(j)}^{i}$ with respect to $j^{\text {th }}$ bus voltage. The equations 7 and 8 , results in positive values when $j^{\text {th }}$ VSC is drawing real current and inductive reactive current.

The various operating combinations of VSC based HVDC

\begin{tabular}{|c|c|c|c|c|}
\hline \multirow[t]{2}{*}{ Case } & \multicolumn{2}{|c|}{ VSC1 (Rectifier) } & \multicolumn{2}{|c|}{ VSC2 (Inverter) } \\
\hline & Controller-1 & Controller-2 & Controller-1 & Controller-2 \\
\hline 1 & Power & Reactive current & DC voltage & Reactive current \\
\hline 2 & Power & Bus voltage & DC voltage & Bus voltage \\
\hline 3 & DC voltage & Reactive current & Power & Reactive current \\
\hline 4 & DC voltage & Bus voltage & Power & Bus voltage \\
\hline
\end{tabular}
are summarized in Table $\mathbf{I}$.

TABLE I

OPERATING COMBINATIONS OF VSC BASED HVDC

Additional 4 cases (cases 5-8) are obtained when VSC1 operates as an inverter and VSC2 operates as a rectificr.

\section{Optimization of the Control.ler Parameters}

With 4 controllers at each converter station there can be up to 17 controller gains to be selected for a two terminal VSC base HVDC link. Each operating mode requires proper tuning of controller gains in order to achieve satisfactory system performance.

A systematic approach for parameter optimization [4] in selecting controller gains of VSC based HVDC is discussed in the section to follow.

\section{A. Statement of the optimization problem}

Consider a system defined by the equation

$$
\begin{array}{r}
\dot{X}=[A(r)] X \\
Y=[C] X
\end{array}
$$

where matrix $[A(r)]$ involves one or more adjustable parameters. $[r]$ is the vector of controller gains to be optimized. The optimization problem is based on the standard infinite time quadratic performance index which is to be minimized by adjusting the controller parameters and can be stated as,

$$
J=\int_{t}^{\infty} Y^{t} Y d t
$$

Assuming the system is stable, $J$ can be expressed as

$$
J=X^{T} P X
$$

where $P$ is a positive definite matrix and solved from the Liapunov equation

$$
P A+A^{T} P=-Q
$$

where $Q=C^{t} C$

$$
\text { At } t=0 \text {, }
$$

$$
J=X_{0}^{T} P X_{0}
$$

If $X_{0}$ lies on the hypersphere of radius unity, the expected value of $J$ can be expressed as,

$$
\widehat{J}==\operatorname{tr}[P]
$$

\section{B. Algorithm for optimization}

The performance index $\widehat{J}$ given by equation (18) can be obtained in terms of the initial state $X_{0}$ and initial values of the controller parameters $\left[r_{0}\right]$ which are determined by trial and error. The algorithm for minimization is given as below.

1) Assume $\left[r_{(k)}\right]=\left[r_{0}\right]$.

2) Solve for $[P]$ from equation (16).

3) Calculate $\widehat{J}=\operatorname{tr}[P]$

4) Update $\left[r_{(k+1)}\right]=\left[r_{(k)}\right]+\Delta r_{k}$

5) Test for convergence. If converged stop. Else go to step2.

The parameters are optimized within the range of upper and lower bounds. The upper and lower bounds for parameters are determined to ensure a stable system. The above algorithm is implemented using the optimization routine 'fmincon' of MATLAB [12] where the update for the parameters $\Delta r_{k}$ are obtained by line search.

\section{CASE STUDY}

The system diagram is shown in Fig. 4, which consists of a generator and AC transmission system on either side of VSC HVDC cable transmission. The generator data is adapted from IEEE FBM [9], [13]. The data for HVDC cable transmission is adapted from [14]. The data for the transmission line parameters is given in Appendix-B.

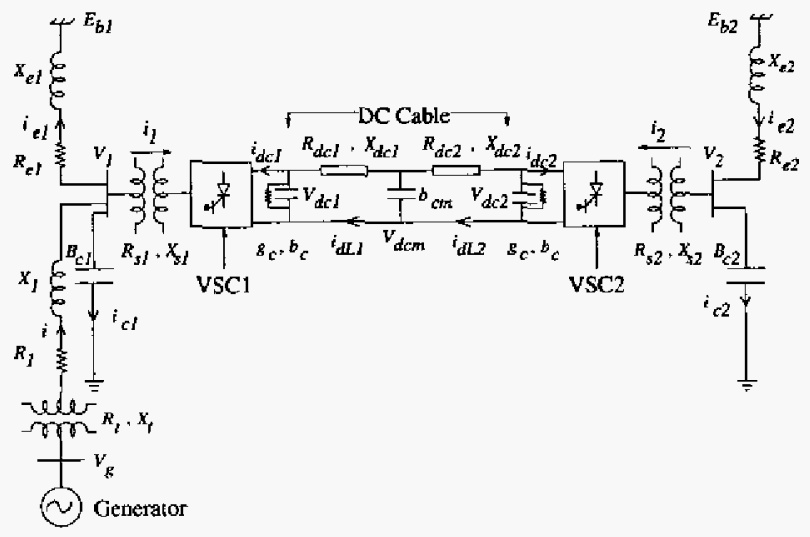

Fig. 4. System diagram 
The modelling aspects of the electromechanical system comprising the generator modelled with 2.2 model, mechanical system, the excitation system, power system stabilizer (PSS), torsional filter and the transmission line are given in detail in reference [8], [9].

The analysis is carried out on the test system based on the following initial operating condition and assumptions.

1) The generator delivers 0.125 p.u. power to the transmission system

2) The magnitude of generator terminal voltage is set at 1.05 p.u.

3) The magnitude of both the converter bus voltages are set at 1.01 p.u. The magnitudes of both the infinite bus voltages are set at 1.0 p.u.

4) The VSCl draws 0.9 p.u. power from busl to feed to HVDC cable for rectifier operation and draws -0.9 p.u. power from bus 1 with inverter operation. The base MVA is $300 \mathrm{MVA}, \mathrm{AC}$ voltage base is taken to be $500 \mathrm{kV}$ and DC voltage base is $150 \mathrm{kV}$.

5) Generator rating is taken to be $300 \mathrm{MVA}$ in all case studies.

\section{A. Simulation results}

The initial values of parameters are suboptimal and are obtained by trial and error. To study the performance of controller and optimize the performance, a step change in the reference is applied and the simulation results for suboptimal and optimum controller parameters (obtained by the algorithm) are given in the sections to follow.

The simulation results for step change in reactive current and power reference of VSCI with case-1 (when the controller parameters are suboptimal) are shown in Fig. 5.
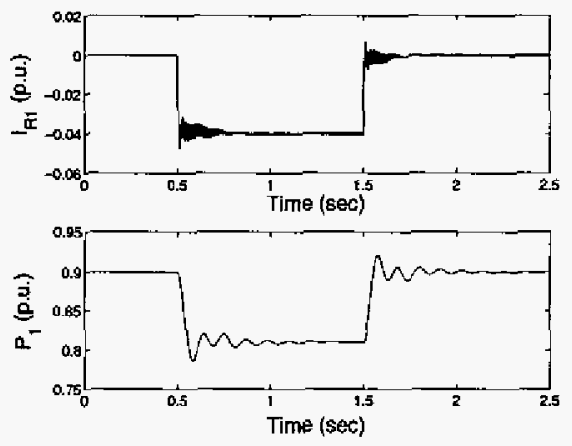

Fig. 5. Simulation results for step change with suboptimal controller parameters (case-1)

The simulation results for step change in reactive current and power reference of VSC1 with case-1 (when the controller parameters are optimal) are shown in Fig. 6. The optimal parameters obtained for case- 1 can be used with case- 2 as the only difference with this case is that, the reactive current reference is obtained from bus voltage controller.

The simulation results with case- 3 for step change in reactive current of VSC1 and power reference using the optimal
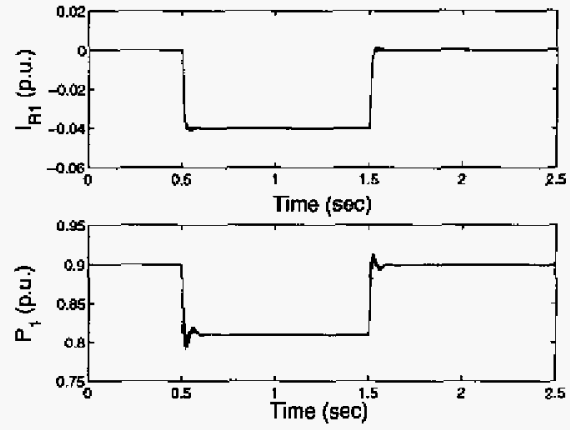

Fig. 6. Simulation results for step change with optimal controlles parameters (case-1)

parameters obtained for case- 1 are shown in Fig. 7. It is to be noted that, the system is unstable and the optimal parameters of case-1 operation are found unsuitable for case-3. Hence for case-3 operation, the optimal parameters are separately obtained.
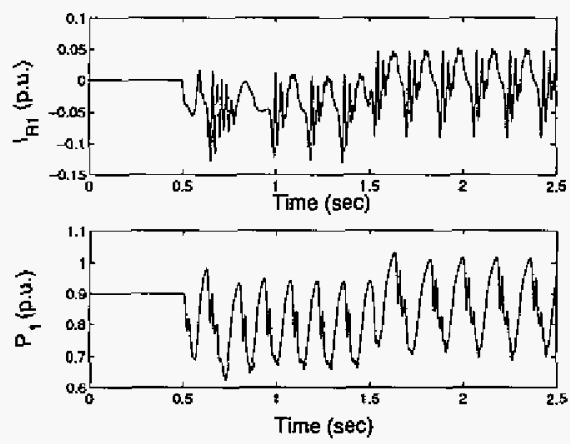

Fig. 7. Simulation results for step change with case-3 using the optimal controller parameters of case-1

The simulation results for step change in reactive current of VSC1 and power reference with case-3 (when the controller parameters are optimal) are shown in Fig. 8. It is observed that, the response to step change in power is slow with rectifier on voltage control and inverter on power control (case-3) compared with case-1. This is observed (results not shown here) even when VSC1 is operating as an inverter and VSC2 as rectifier. In general, the controller gains for different operating modes are simillar only when the change pertains to the operation of the reactive current control.

\section{B. Eigenvalue Analysis}

In this analysis, the overall system is linearized at the operating point and the eigenvalues of system matrix are computed for cases 1-8 and are given in Table II. Comparing the eigenvalue results of Table II, it is to be noted that, the voltage control marginally improves the damping of swing mode with rectifier operation of VSC1 whereas, it marginally reduces the damping of swing mode with inverter operation 

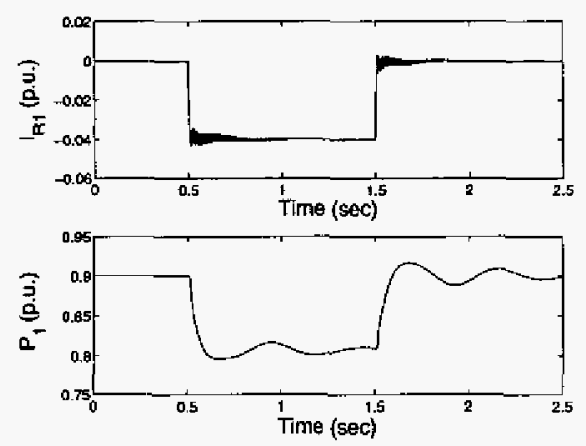

Fig. 8. Simulation results for step change with optimal controller parameters (case-3)

of VSC1. In general, inverter operation improves the damping of swing mode than rectifier operation.

TABLE II

EJGENVALUES OF THE DETAILED SYSTEM

\begin{tabular}{|c|c|}
\hline \hline Cuse & Swing mode \\
\hline 1 & $-1.0512 \pm j 7.4987$ \\
\hline 2 & $-1.0816 \pm j 7.5319$ \\
\hline 3 & $-1.0743 \pm j 7.5291$ \\
\hline 4 & $-1.0834 \pm j 7.5390$ \\
\hline 5 & $-1.1553 \pm j 7.4895$ \\
\hline 6 & $-1.1389 \pm j 7.5117$ \\
\hline 7 & $-1.1859 \pm j 7.3823$ \\
\hline 8 & $-1.1233 \pm j 7.4699$ \\
\hline
\end{tabular}

\section{Transient simulation}

The transient simulation of the combined nonlinear system with $\mathrm{D}-\mathrm{Q}$ and detailed three phase model of the system is carried out using MATLAB-SIMULINK [12].

A large disturbance is initiated at $0.5 \mathrm{sec}$ in the form of three phase fault at converter- 1 bus of VSC HVDC with a fault reactance of 0.04 (p.u.) and cleared at 4.0 cycles.

The simulation results for case- 1 with D-Q model of VSC HVDC are shown in Fig. 9. The simulation results for case-1 with three phase model of VSC HVDC are shown in Fig. 10. It is to be noted that, there is a good match between the simulation results (variation of rotor angle $(\delta)$ and power of converter $1\left(P_{1}\right)$ ) obtained with $\mathrm{D}-\mathrm{Q}$ and three phase models of VSC HVDC. Also, the power flow in the HVDC link is brought back to the reference value in a short time.

\section{Conclusion}

In this paper, we have presented the analysis and simulation of VSC based HVDC system. The morlelling details of HVDC system with twelve-pulse three level VSC are discussed. A systematic approach for the selection of controller parameters based on parameter optimization is presented.

The following points emerge based on eigenvalue analysis and transient simulation.

1) The optimal controller gains depend significantly on the location of the de voltage controller. The response of
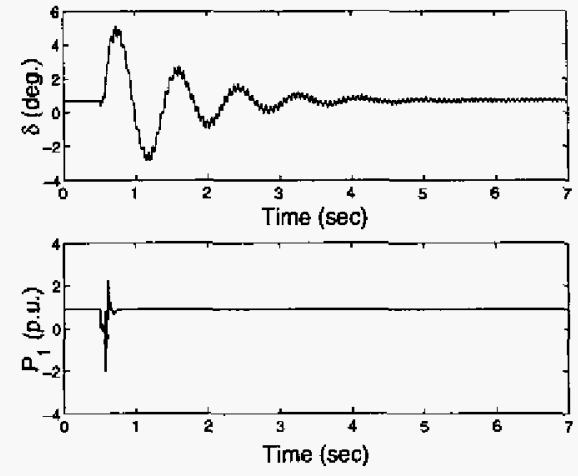

Fig. 9. Variation of rotor angle and power at converter 1 for three phase fault (D-Q model)
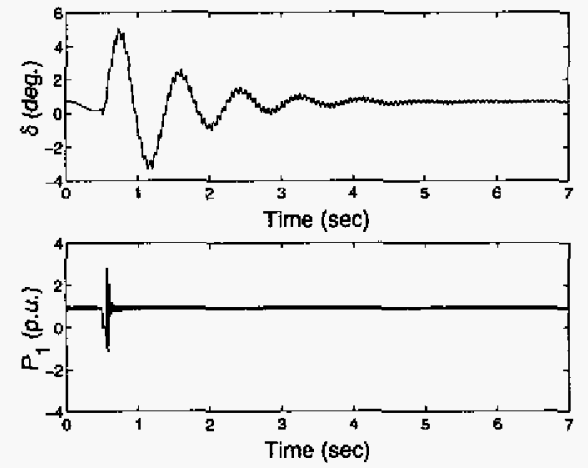

Fig. 10. Variation of rotor angle and power at converter 1 for three phase fault (Three phase model)

the power controller becomes slow if the dc voltage controller is located at the rectifier station.

2) Although, the inverter operation improves slightly the damping of swing mode than rectifier operation, the mode of operation of VSC based HVDC system has no significant effect on the damping of generator swing mode.

3) The $D-Q$ model is quite accurate in predicting the system performance.

\section{APPENDIX A}

SWITCHING FUNCTIONS FOR A THREE LEVEL, VSC

In three level bridge, the phase potentials can be modulated between three levels instead of two. Each phase can be connected to the positive de terminal, the midpoint on the dc side or the negative dc terminal. The switching function $P_{a}(t)$ for phase ' $a$ ' is shown in Fig. 11. The switching functions of phase $b$ and $c$ are similar but phase shifted successively by $120^{\circ}$ in terms of the fundamental frequency.

The converter terminal voltages with respect to the neutral of transformer can be expressed as, 


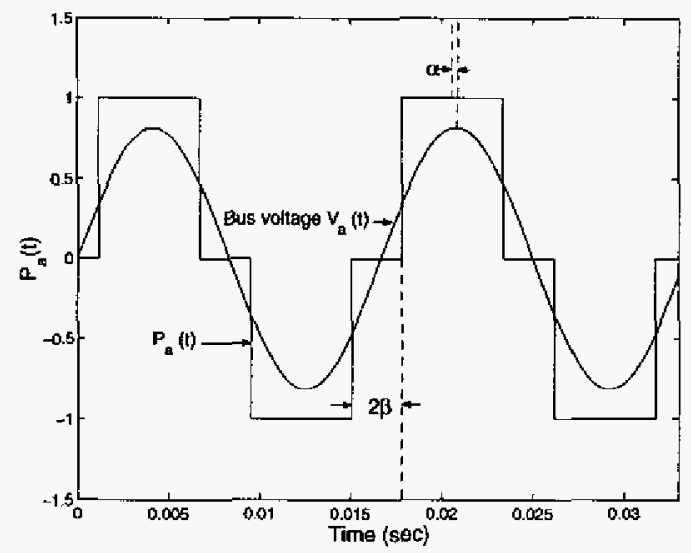

Fig. 11. Switching function for a three level converter

$$
\left[\begin{array}{c}
v_{a n}^{i} \\
v_{b n}^{i} \\
v_{c n}^{i}
\end{array}\right]=\left[\begin{array}{l}
S_{a}(t) \\
S_{b}(t) \\
S_{c}(t)
\end{array}\right] V_{d c}
$$

where, $S_{a}(t)=\frac{P_{\mathrm{a}}(t)}{2}-\left[\frac{P_{a}(t)+P_{b}(t)+P_{c}(t)}{6}\right]$ $S_{a}(t)$ is the switching function for phase ' $a$ ' of a 6-pulse 3level VSC and $V_{d c}$ is the dc side capacitor voltage. Similarly for phase 'b', $S_{b}(t)$ and for phase 'c', $S_{c}(t)$ can be derived. The peak value of the fundamental and harmonics in the phase voltage $v_{a n}^{i}$ are found by applying Fourier analysis on the phase voltage and can be expressed as,

$$
V_{a n(h)}^{i}=\frac{2}{h \pi} V_{d c} \cos (h \beta)
$$

Where, $h=1,5,7,11,13$ and $\beta$ is the dead angle (period) during which the converter pole output voltage is zero. We can eliminate the 5 th and 7th harmonics by using a twelve-pulse VSC, which combines the output of two six-pulse converters using transformers. The switching functions for a twelve-pulse converter are given by,

$S_{a}^{22}(t)=S_{a}(t)+\frac{1}{\sqrt{3}}\left(S_{a}^{\prime}(t)-S_{c}^{\prime}(t)\right)$

$S_{b}^{12}(t)=S_{b}(t)+\frac{1}{\sqrt{3}}\left(S_{b}^{\prime}(t)-S_{a}^{\prime}(t)\right)$,

$S_{c}^{12}(t)=S_{c}(t)+\frac{1}{\sqrt{3}}\left(S_{c}^{\prime}(t)-S_{b}^{\prime}(t)\right)$

where $S_{x}^{\prime}(t)=S_{x}\left[t+\frac{2 \pi}{\omega_{0}} \frac{1}{12}\right], x=a, b$ and $c$. If the switching functions are approximated by their fundamental components (neglecting harmonics) for a 12-pulse three level converters, we get

$$
v_{a n}^{i}=\frac{4}{\pi} V_{d c} \cos (\beta) \sin \left(\omega_{o} t+\theta+\alpha\right)
$$

and $v_{b n}^{i}, v_{c n}^{i}$ are phase shifted successively by $120^{\circ}$.

The bus voltage $v_{a}$ is given by $v_{a}=\sqrt{\frac{2}{3}} V \sin \left(\omega_{o} t+\theta\right)$ and $v_{b}, v_{c}$ are phase shifted successively by $120^{\circ}$.

Note that $\alpha$ is the angle by which the fundamental component of converter output voltage leads the respective bus voltages.
Neglecting converter losses we can get the expression for dc side currents as,

$$
\left[i_{d c}\right]=-\rho \frac{V_{d c b}}{V_{a c b}}\left[\begin{array}{l}
S_{a}^{12}(t) \\
S_{b}^{12}(t) \\
S_{c}^{12}(t)
\end{array}\right]^{t}\left[\begin{array}{l}
i_{a} \\
i_{b} \\
i_{c}
\end{array}\right]
$$

where $\rho$ is the transformation ratio of the interfacing transformer of VSC.

\section{APPENDIX B \\ SYSTEM DATA}

The data for generator in per unit are given in references [9], [13]. All data are in p.u. on 300 MVA base.

Transmission system data (300MVA, 500kV):

$R_{t}=0.0, X_{t}=0.14, R_{1}=0.02, X_{1}=0.5, B_{C 1}=0.3$

$R_{e 1}=0.02, X_{e 1}=0.28059, R_{e 2}=0.02, X_{e 2}=0.30$,

$B_{C 2}=0.3$

$V_{g}=1.05 \angle \theta_{g}, V_{1}=1.01 \angle \theta_{1}, V_{2}=1.01 \angle \theta_{2}$

$E_{b 1}=1 \angle 0^{\circ}, E_{b 2}=1 \angle 0^{0}$

VSC data:

$R_{s}=0.0064, X_{s}=0.096, R_{p}=50.368, g_{c}=\frac{1}{R_{p}}$, $b_{c}=1.775$

DC Cable data (300MW, $150 \mathrm{kV}$ base):

$R_{d c 1}=0.0333, X_{d c 1}=3, R_{d c 2}=0.0333, X_{d c 2}=3$, $b_{c m}=0.73513$

\section{REFERENCES}

[1] G. Asplund, K. Eriksson and K. Stevenson, "DC transmission based on voltage source converters", CIGRE SC14 Colloquium, South Africa, 1997.

[2] Byggeth M. et al., "GOTLAND HVDC LIGHT - the world's first commercial extruded HVDC cable system", CIGRE, Paris, August 2000, paper 14-205.

[3] B. T. Ooi and X. Wang, "Voltage angle lock loop control of the boost type PWM Converter for HVDC application", IEEE Transactions on Power Electronics, Vol. 5. No. 2 po. 229-235, April 1990.

[4] William $\mathbf{S}$. Levine and Michael Athans, "On the Determination of the Optimal Constant Output Feedback Gains for Linear Multivariable Systems", IEEE Transacions on Automatic Control, Vol. AC-15, No. 1, pp. 44-48, Feb. 1970.

[5] N. G. Hingorani and L. Gyugyi, Understanding FACTS, New York: IEEE Press, 2000

[6] Kalyan K. Sen and Eric J. Stacy, "UPFC- Unified Power Flow Controller: Theory, Modelling and Applications", IEEE Transactions on Power Delivery, Vol.13, No.4, pp. 1453-1460, October 1998.

[7] K. R. Padiyar and Nagesh Prabhu, "Analysis of Subsynchronous Resonance with Three Level Twelve-Pulse VSC based SSSC", IEEE TENCON-2003, pp. 76-80, 14-17 October 2003.

[8] K. R. Padiyar, Power System Dynamics - Stability and Control-Second edition, Hyderabad: B.S.Publications, 2002.

[9] K. R. Padiyar, Analysis of Subsynchronous Resonance in Power Systems, Boston: Kluwer Academic Publishers, 1999.

[10] Schauder and Mehta, "Vector Analysis and Control of Advanced Static VAR Compensators", IEE Proc.-c, Vol.140, No.4, pp. 299-306, July 1993.

[11] K. R. Padiyar and A. M. Kulkami, "Control Design and Simulation of Unified Power Flow Controller", IELE Transactions on Power Delivery. Vol.13, No.4, pp. 1348-1354, October 1998.

12] The Math Works ]nc, "Using MATLAB-SIMULINK", 1999

[13] IEEE Committee Report, "First Benchmark Model for Computer Simulation of Subsynchronous Resonance," IEEE Transactions on Power Apparatus and Systems, Vol. PAS-96, No.5, pp. 1565-1572, sep/oct 1 c.77.

[14] T. Wess et.al., "Control Performance on HVDC Benchmark Models", International Calloquium on HVDC Power Transmission, pp. II-3-II-10, 9-11 Sep. 2003. New Delhi. INDIA. 